\title{
Magnetic properties, phase evolution and microstructure of directly quenched bulk $\mathrm{Pr}-\mathrm{Fe}-\mathrm{B}-\mathrm{Nb}$ magnets
}

\author{
H.W. Chang, ${ }^{\mathrm{a}, \mathrm{b}, *}$ M.F. Shih, ${ }^{\mathrm{a}}$ C.W. Chang, ${ }^{\mathrm{a}}$ C.C. Hsieh, ${ }^{\mathrm{a}}$ Y.T. Cheng, ${ }^{\mathrm{a}}$ W.C. Chang, ${ }^{\mathrm{a}, *}$ \\ A.C. Sun $^{\mathrm{c}}$ and Y.D. Yao \\ a Department of Physics, National Chung Cheng University, Chia-Yi, Taiwan \\ ${ }^{\mathrm{b}}$ Institute of Physics, Academia Sinica, Nankang, Taipei, Taiwan \\ ${ }^{\mathrm{c}}$ Department of Physics, National Taiwan University, Taipei, Taiwan \\ ${ }^{\mathrm{d}}$ Department of Materials Engineering, Tatung University, Taipei, Taiwan
}

Received 4 December 2007; revised 19 February 2008; accepted 10 March 2008

Available online 15 March 2008

The magnetic properties, phase evolution and microstructure of directly quenched bulk $\operatorname{Pr}_{9.5} \mathrm{Fe}_{90.5-x-y} \mathrm{Nb}_{x} \mathrm{~B}_{y}$ magnets have been studied. Proper $\mathrm{Nb}$ substitution for Fe at a high $\mathrm{B}$ concentration can greatly modify the phase constitution and refine the grain size from the micrometer scale to $50-150 \mathrm{~nm}$. Optimal magnetic properties, i.e. $J_{\mathrm{r}}=0.57 \mathrm{~T},{ }_{i} H_{\mathrm{c}}=1296 \mathrm{kA} \mathrm{m}{ }^{-1}$ and $(\mathrm{BH})_{\max }=56.8 \mathrm{~kJ} \mathrm{~m}^{-3}$, were achieved for $\operatorname{Pr}_{9.5} \mathrm{Fe}_{71.5} \mathrm{Nb}_{4} \mathrm{~B}_{15}$. The high coercivity results from the large volume fraction of the 2:14:1 phase, fine grains and the appearance of a grain boundary phase in the magnet.

(C) 2008 Acta Materialia Inc. Published by Elsevier Ltd. All rights reserved.

Keywords: Bulk hard magnets; $\operatorname{Pr}_{2} \mathrm{Fe}_{14} \mathrm{~B}$; Grain refinement

Over the past two decades, two types of exchangecoupled nanocomposites, namely $\alpha-\mathrm{Fe} / \mathrm{R}_{2} \mathrm{Fe}_{14} \mathrm{~B}$ and $\mathrm{Fe}_{3} \mathrm{~B} / \mathrm{R}_{2} \mathrm{Fe}_{14} \mathrm{~B}$ ( $\mathrm{R}=$ rare earth elements), have been widely investigated for bonded magnet applications because they have high maximum energy product $\left((\mathrm{BH})_{\max }\right)$, high coercivity, relatively low rare earth contents and better chemical stability [1-8]. Traditionally, bonded magnets have been produced by molding powders obtained by crushing melt spun ribbons fabricated at an optimal quenching velocity, followed by postannealing with a polymer binder. The main disadvantages of the traditional method include the number of manufacturing processes and the dilution of magnetic properties by nonmagnetic polymer.

Recently, to overcome these disadvantages, the copper mold casting method has been adopted: this initially produces a bulk amorphous precursor which then undergoes a one-step heat treatment to optimize the permanent magnetic properties [9-13]. Research has concentrated on compositions with very high $\mathrm{B}$ and low rare earth element content, such as $\mathrm{R}_{3-4.5} \mathrm{Fe}_{\text {bal. }} \mathrm{M}_{x} \mathrm{~B}_{20} \quad(\mathrm{R}=\mathrm{Pr}$, $\mathrm{Pr}+\mathrm{Dy}, \mathrm{Nd}+\mathrm{Dy} ; \mathrm{M}=\mathrm{Co}, \mathrm{Cu}, \mathrm{Mo}, \mathrm{Nb}, \mathrm{Ti}, \mathrm{V}$ and

\footnotetext{
* Corresponding authors. Address: Department of Physics, National Chung Cheng University, Chia-Yi, Taiwan; e-mail addresses: stick@phys.sinica.edu.tw; phywcc@ccu.edu.tw
}

$\mathrm{Zr}$ ), in order to produce a bulk amorphous precursor in rod form, typically $0.5-0.6 \mathrm{~mm}$ in diameter, which was then annealed at $600-700{ }^{\circ} \mathrm{C}$ for $10-30 \mathrm{~min}$ [9-13]. Unfortunately, the experimental results showed that the intrinsic coercivity $\left({ }_{i} H_{\mathrm{c}}\right)$ is too low $\left(<300 \mathrm{kA} \mathrm{m}^{-1}\right)$ to be suitable for high-temperature applications, even though a relatively high $(\mathrm{BH})_{\max }$ of $58-96 \mathrm{~kJ} \mathrm{~m}^{-3}$ can be attained [9-13]. This lower ${ }_{i} H_{\mathrm{c}}$ results from the existence of a considerable volume fraction of the magnetically soft $\mathrm{Fe}_{3} \mathrm{~B}$ and/or $\alpha$-Fe phases. Zhang et al. reported that a high coercivity of $1100 \mathrm{kA} \mathrm{m}^{-}$can be obtained for bulk $\mathrm{Nd}_{9.6} \mathrm{Fe}_{\text {bal. }} \mathrm{Nb}_{4} \mathrm{~B}_{22.08}$ magnet, but the energy product is relatively very low $\left(33 \mathrm{~kJ} \mathrm{~m}^{-3}\right)$ [14].

Many other previous papers have reported that the $\mathrm{R}$-poor and $\mathrm{B}$-enriched $\mathrm{R}_{8-11} \mathrm{Fe}_{\text {bal. }} \mathrm{M}_{2} \mathrm{~B}_{10-15}$ alloys with refractory element $(\mathrm{R}=\operatorname{Pr}$ or $\mathrm{Nd} ; \mathrm{M}=\mathrm{Ti}, \mathrm{Nb}, \mathrm{V}$ or $\mathrm{Zr}$ ) substitution exhibit simultaneously both high $(\mathrm{BH})_{\max }$ and high coercivity $\left({ }_{i} H_{\mathrm{c}}\right)$, in ribbon form, arising from appropriate volume fractions of magnetically soft and hard phases, the uniform fine grains and the existence of a thin grain boundary phase.[15-23] Of all the refractory elements studied, $\mathrm{Nb}$ is the most effective in reducing the grain size $[18,19,22,23]$ and increasing the glass formability for bulk metallic glass (BMG)-forming alloy systems.[24] Furthermore, the B content is crucial in modifying the microstructure of $\mathrm{R}_{2} \mathrm{Fe}_{14} \mathrm{~B}$-type 
nanocomposites [17] and also the glass formability of BMGs $[9,14,24]$.

In order to explore the possibility of further simplifying the manufacturing process and obtaining isotropic bulk magnets with both high ${ }_{i} H_{\mathrm{c}}$ and high $(\mathrm{BH})_{\max }$, we adopted the copper mold casting method to fabricate bulk $\mathrm{Pr}-\mathrm{Fe}-\mathrm{Nb}-\mathrm{B}$ magnets, in rod form with a diameter of $0.7 \mathrm{~mm}$, without any post-casting heat treatment. In addition, the effects of $\mathrm{Nb}$ substitution for Fe and of varying the $\mathrm{B}$ content on the magnetic properties, phase evolution and microstructure of bulk $\mathrm{Pr}_{9.5} \mathrm{Fe}_{90.5-x-y} \mathrm{Nb}_{x} \mathrm{~B}_{y}$ magnets are reported.

Alloy ingots with nominal compositions of $\operatorname{Pr}_{9.5} \mathrm{Fe}_{90.5-x-y} \mathrm{Nb}_{x} \mathrm{~B}_{y} \quad(x=0-5 ; y=12-18)$ were prepared by arc melting mixtures of pure $\mathrm{Pr}, \mathrm{Fe}$ and $\mathrm{Nb}$ metals and pure B crystal in an argon atmosphere. $5 \%$ excess Pr was added to compensate for the loss of Pr during processing. Magnetic cylindrical rods $(0.7 \mathrm{~mm}$ diameter $\times 10 \mathrm{~mm}$ length) were obtained by injecting the melt into a copper mold. The Curie temperatures of the magnetic phases were determined by thermogravimetric analysis (TGA) with an externally applied magnetic field (conventionally referred to as "TMA"), at a heating rate of $20^{\circ} \mathrm{C} \mathrm{min}^{-1}$. The magnetic properties of the rods at room temperature were measured with a vibrating sample magnetometer (VSM). All samples were magnetized by a $50 \mathrm{kOe}$ peak pulse field prior to magnetic measurement. The macroscopic morphology of the cross-section of the bulk magnets was investigated using scanning electron microscopy (SEM), and the microstructure was observed directly by transmission electron microscopy (TEM).

The effect of $\mathrm{Nb}$ content on the magnetic properties and phase evolution of directly quenched $\operatorname{Pr}_{9.5^{-}}$ $\mathrm{Fe}_{75.5-x} \mathrm{Nb}_{x} \mathrm{~B}_{15}$ magnets was investigated. Figure 1 shows the demagnetization curves of $\operatorname{Pr}_{9.5} \mathrm{Fe}_{75.5-x} \mathrm{Nb}$ ${ }_{x} \mathrm{~B}_{15}(x=0-5)$ magnets. For a ternary $\operatorname{Pr}_{9.5} \mathrm{Fe}_{75.5} \mathrm{~B}_{15}$ alloy rod, rather poor magnetic properties of $J_{\mathrm{r}}=$ $0.6 \mathrm{~T},{ }_{i} H_{\mathrm{c}}=760 \mathrm{kA} \mathrm{m}^{-1}$ and $(\mathrm{BH})_{\max }=28 \mathrm{~kJ} \mathrm{~m}^{-3}$ were obtained due to the poor squareness (SQ) of its demagnetization curve. It is clear that the substitution of $\mathrm{Nb}$ for $\mathrm{Fe}$ in directly quenched $\operatorname{Pr}_{9.5} \mathrm{Fe}_{75.5-x} \mathrm{Nb}_{x} \mathrm{~B}_{15}$ magnets substantially improved ${ }_{i} H_{\mathrm{c}}$ and $\mathrm{SQ}$, resulting in the enhancement of $(\mathrm{BH})_{\max }$. When the $\mathrm{Nb}$ content $x$ was increased, ${ }_{i} H_{\mathrm{c}}$ and $(\mathrm{BH})_{\max }$ also increased up to

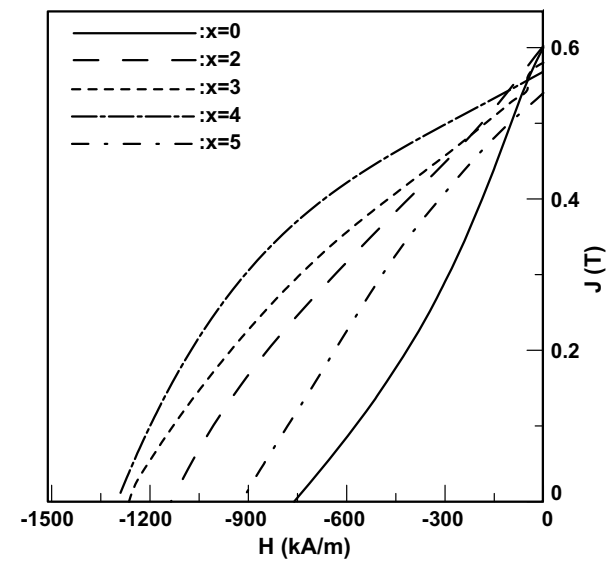

Figure 1. Demagnetization curves for directly quenched bulk $\operatorname{Pr}_{9.5} \mathrm{Fe}_{75.5-x} \mathrm{Nb}_{x} \mathrm{~B}_{15}$ magnets with a diameter of $0.7 \mathrm{~mm}$. maximum respective values of $1296 \mathrm{kA} \mathrm{m}^{-1}$ and $56.8 \mathrm{~kJ} \mathrm{~m}^{-3}$ for $x=4$, beyond which they then decreased to $920 \mathrm{kA} \mathrm{m}^{-1}$ and $41.6 \mathrm{~kJ} \mathrm{~m}^{-3}$, respectively, for $x=5$; on the other hand, the remanent magnetization $\left(\mathrm{J}_{\mathrm{r}}\right)$ decreased monotonically from $0.6 \mathrm{~T}$ for $x=0$ to $0.54 \mathrm{~T}$ for $x=5$. This reflects the fact that substitution of suitable amounts of $\mathrm{Nb}$ for $\mathrm{Fe}$ in bulk $\operatorname{Pr}_{9.5} \mathrm{Fe}_{75.5-x} \mathrm{Nb}_{x} \mathrm{~B}_{15}$ magnets is effective in enhancing both ${ }_{i} H_{\mathrm{c}}$ and $(\mathrm{BH}) \max$.

In X-ray diffraction (XRD) studies of R-poor and Benriched RFeB alloys, the diffraction peaks for the 2:14:1 phase usually overlapped with those for the 2:23:3, $\mathrm{Fe}_{3} \mathrm{~B}, \alpha-\mathrm{Fe}$ or other phases present, which complicated the phase identification [7,15-21]. Hence, the TMA technique was adopted in an attempt to understand the magnetic phase constitution of directly quenched magnets in this study. Figure 2 presents TMA scans for directly quenched bulk $\operatorname{Pr}_{9.5} \mathrm{Fe}_{75.5-x} \mathrm{Nb}_{x} \mathrm{~B}_{15} \quad(x=0-5)$ magnets. For the ternary $\operatorname{Pr}_{9.5} \mathrm{Fe}_{75.5} \mathrm{~B}_{15}$ magnet, in addition to $\operatorname{Pr}_{2} \mathrm{Fe}_{14} \mathrm{~B}, \mathrm{Fe}_{3} \mathrm{~B}$, and $\alpha-\mathrm{Fe}$, an unknown phase with $T_{\mathrm{C}} \sim 570^{\circ} \mathrm{C}$ was found. Clearly, this unknown phase was largely suppressed and also the volume fraction of $\alpha$-Fe phase was reduced, consistent with the presence of a large volume fraction of 2:14:1 phase in the magnet, induced by $\mathrm{Nb}$ substitution, and resulting in a remarkably increase in coercivity. It is seen that with the increment of $\mathrm{Nb}$ content $x$, the $T_{\mathrm{C}}$ for the $2: 14: 1$ phase slightly decreased from $291{ }^{\circ} \mathrm{C}$ for $x=0$ to $287^{\circ} \mathrm{C}$ for $x=4$, and was then comparatively much reduced to $278^{\circ} \mathrm{C}$ for $x=5$, implying that some of the $\mathrm{Nb}$ atoms might have entered the crystal structure of the 2:14:1 phase for magnets with higher $\mathrm{Nb}$ content. The reduction of remanence with $\mathrm{Nb}$ content could be attributed mainly to the increased volume fraction of the 2:14:1 phase and also the magnetic dilution of nonmagnetic $\mathrm{Nb}$ element in the 2:14:1 phase. Moreover, a larger proportion of $\mathrm{Fe}_{3} \mathrm{~B}$ phase was present in the magnets with higher $\mathrm{Nb}$ content, i.e. $x=5$. This explains why all the hard magnetic properties were decreased for higher $\mathrm{Nb}$ content, i.e. $x=5$.

It is well known that a very fine microstructure is necessary to obtain excellent magnetic performance for

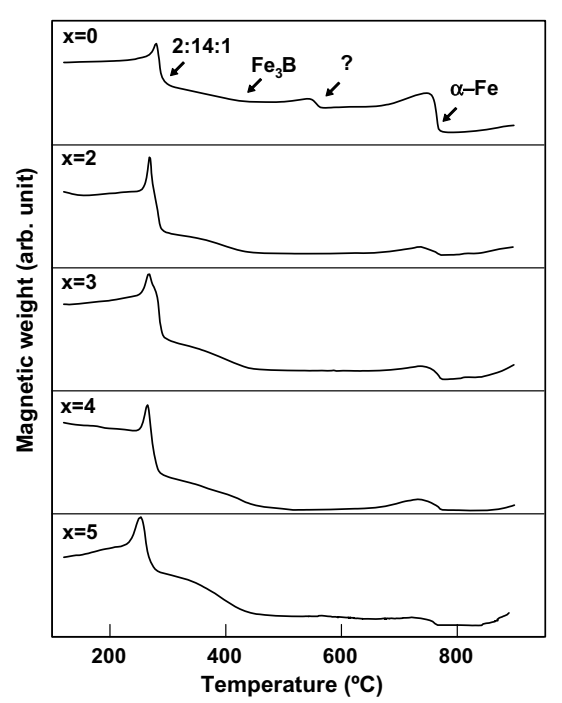

Figure 2. TMA scans for directly quenched $\operatorname{Pr}_{9.5} \mathrm{Fe}_{75.5-x} \mathrm{Nb}_{x} \mathrm{~B}_{15}$ magnets. 


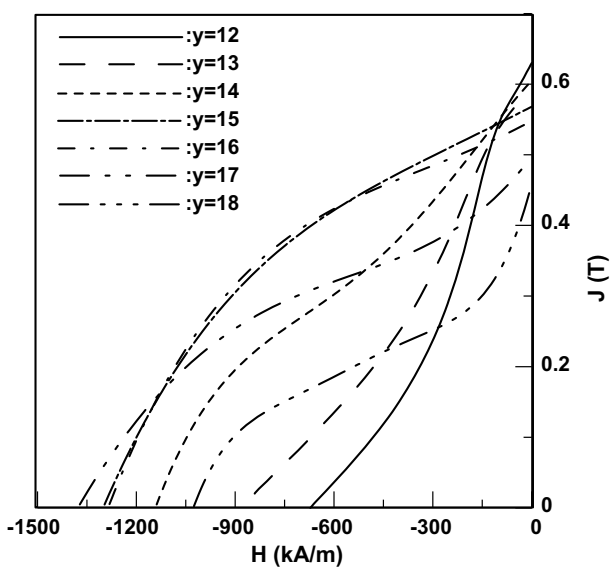

Figure 3. Demagnetization curves for directly quenched $\mathrm{Pr}_{9.5} \mathrm{Fe}_{86.5-y} \mathrm{Nb}_{4} \mathrm{~B}_{y}$ magnets.

isotropic $\mathrm{R}_{2} \mathrm{Fe}_{14} \mathrm{~B}$-type nanocomposites, and the $\mathrm{B}$ content is crucial in favourably modifying the microstructure for nanocomposites [17] and the glass formability for BMGs $[9,14,22]$. Therefore, the effect of B content on the magnetic properties and phase evolution of directly quenched $\mathrm{Pr}_{9.5} \mathrm{Fe}_{86.5-y} \mathrm{Nb}_{4} \mathrm{~B}_{y}$ magnets was also studied. Figure 3 shows their second quadrant demagnetization curves, and their magnetic properties are summarized and listed in Table 1. Clearly, with increasing B content $y,{ }_{i} H_{\mathrm{c}}$ increased from $672 \mathrm{kA} \mathrm{m}^{-1}$ for $y=12$ to $1376 \mathrm{kA} \mathrm{m}^{-1}$ for $y=17$, but then decreased to $1024 \mathrm{kA} \mathrm{m}^{-1}$ for $y=18$. In contrast, $\mathrm{J}_{\mathrm{r}}$ decreased monotonically from $0.63 \mathrm{~T}$ for $y=12$ to $0.47 \mathrm{~T}$ for $y=18$. On the other hand, SQ improved on increasing $y$ from 12 to 15 , but deteriorated when $y$ increased further to 18 . Accordingly, $(\mathrm{BH})_{\max }$ increased from $44 \mathrm{~kJ} \mathrm{~m}^{-3}$ for $y=12$ to reach a maximum value of $56.8 \mathrm{~kJ} \mathrm{~m}^{-3}$ for $y=15$, and then decreased to $23.2 \mathrm{~kJ} \mathrm{~m}^{-3}$ for $y=18$. This suggests that control of $\mathrm{B}$ content is important for obtaining directly quenched $\mathrm{Pr}_{9.5} \mathrm{Fe}_{86.5-x} \mathrm{Nb}_{4} \mathrm{~B}_{y}$ magnets with higher ${ }_{i} H_{\mathrm{c}}$ and $(\mathrm{BH})_{\max }$. For the alloys studied here, the optimal magnetic properties of $J_{\mathrm{r}}=0.57 \mathrm{~T}$, ${ }_{i} H_{\mathrm{c}}=1296 \mathrm{kA} \mathrm{m}^{-1}$ and $(\mathrm{BH})_{\max }=56.8 \mathrm{~kJ} \mathrm{~m}^{-3}$ were achieved for the $\operatorname{Pr}_{9.5} \mathrm{Fe}_{71.5} \mathrm{Nb}_{4} \mathrm{~B}_{15}$ magnet. It is noteworthy that these directly quenched $\mathrm{Pr}_{9.5} \mathrm{Fe}_{90.5} \mathrm{Nb}{ }_{x} \mathrm{~B}_{y}$ rods with a diameter of $0.7 \mathrm{~mm}$ simultaneously exhibited high coercivity and energy product.

Figure 4 presents TMA scans for bulk $\operatorname{Pr}_{9.5^{-}}$ $\mathrm{Fe}_{86.5-y} \mathrm{Nb}_{4} \mathrm{~B}_{y}$ magnets. It was found that the large volume fraction of magnetically hard 2:14:1 phase coexisted with minor amounts of soft $\mathrm{Fe}_{3} \mathrm{~B}$ and $\alpha$-Fe phases in this series of magnets. In addition, the volume fraction of the

Table 1. Magnetic properties of directly quenched bulk $\mathrm{Pr}_{9.5} \mathrm{Fe}_{86.5-y} \mathrm{Nb}_{4} \mathrm{~B}_{y}$ magnets with a diameter of $0.7 \mathrm{~mm}$

\begin{tabular}{llll}
\hline$y$ & $\mathrm{~J}_{\mathrm{r}}(\mathrm{T})$ & ${ }_{i} \mathrm{H}_{\mathrm{c}}\left(\mathrm{kA} \mathrm{m}^{-1}\right)$ & $(\mathrm{BH})_{\max }\left(\mathrm{kJ} \mathrm{m}^{-3}\right)$ \\
\hline 12 & 0.63 & 672 & 44.0 \\
13 & 0.61 & 888 & 45.6 \\
14 & 0.61 & 1168 & 51.2 \\
15 & 0.57 & 1296 & 56.8 \\
16 & 0.55 & 1296 & 50.4 \\
17 & 0.50 & 1376 & 35.2 \\
18 & 0.47 & 1024 & 23.2 \\
\hline
\end{tabular}

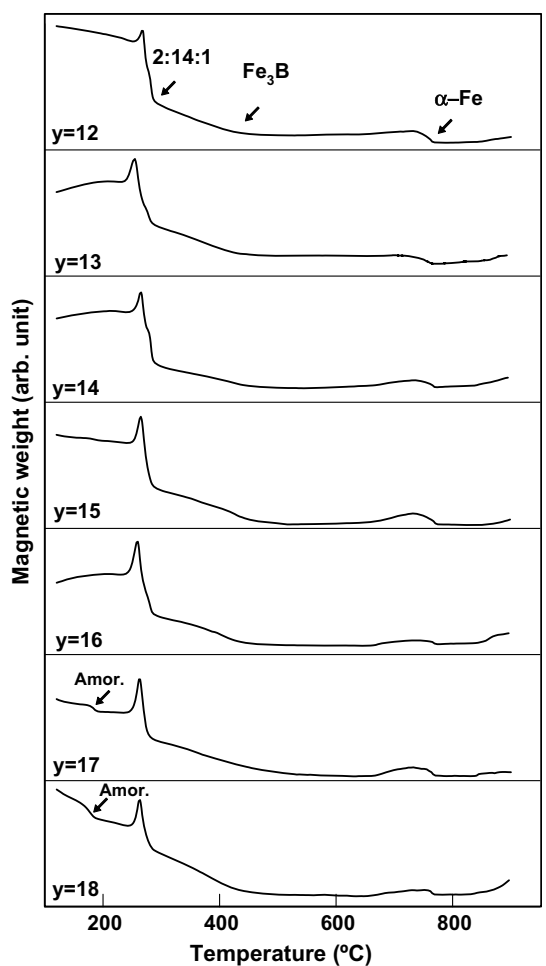

Figure 4. TMA scans for directly quenched $\operatorname{Pr}_{9.5} \mathrm{Fe}_{86.5-y} \mathrm{Nb}_{4} \mathrm{~B}_{y}$ magnets.

2:14:1 phase increased with increasing $\mathrm{B}$ content, giving rise to enhanced ${ }_{i} \mathrm{H}_{\mathrm{c}}$. This is in agreement with our previous study of $\operatorname{Pr}_{9} \mathrm{Fe}_{88.5-x} \mathrm{Ti}_{2.5} \mathrm{~B}_{x}(x=7-15)$ nanocomposite ribbons [17]. However, due to the presence of amorphous phase, the demagnetization curves showed a shoulder phenomenon for magnets with higher B contents of 17-18 at.\%, as shown in Figure 3, resulting in rapid deterioration of the magnetic properties. The decrease in remanence with the increase in B content could be ascribed to two reasons: (i) the increase of volume fraction of magnetically hard 2:14:1 for $y \leqslant 16$; and (ii) the lower SQ of the demagnetization curve due to the weak exchange coupling effect between the 2:14:1 phase and the amorphous phase for $y=17-18$.

The cross-section of the developed bulk magnets has been investigated by SEM, and the morphology normally consisted of a fine-grained peripheral region and a coarse-grained core region. This is in contrast to the morphology observed in the samples with 20 at.\% B $[9,10]$. Since the grain size and its distribution have a large influence on the ${ }_{i} H_{\mathrm{c}}$, SQ and $(\mathrm{BH})_{\max }$ of the magnets, it is necessary to know the grain morphology and grain size, by TEM observation, especially in the core region of the magnets. Figure 5a-c depict TEM images of the core region of directly quenched $\operatorname{Pr}_{9.5} \mathrm{Fe}_{75.5} \mathrm{~B}_{15}$, $\mathrm{Pr}_{9.5} \mathrm{Fe}_{74.5} \mathrm{Nb}_{4} \mathrm{~B}_{12}$ and $\mathrm{Pr}_{9.5} \mathrm{Fe}_{71.5} \mathrm{Nb}_{4} \mathrm{~B}_{15}$ magnetic rods, respectively. The grain sizes for the ternary $\operatorname{Pr}_{9.5} \mathrm{Fe}_{75.5} \mathrm{~B}_{15}$ and the lower $\mathrm{B} \operatorname{Pr}_{9.5} \mathrm{Fe}_{74.5} \mathrm{Nb}_{4} \mathrm{~B}_{12}$ magnets are clearly extremely large and can be estimated to be 400 $1200 \mathrm{~nm}$. However, 4 at.\% substitution of $\mathrm{Nb}$ for $\mathrm{Fe}$ at 15 at.\% B concentration could refine the grain size of the rod down to $50-150 \mathrm{~nm}$. Interestingly, a grain boundary phase was observed in both $\mathrm{Nb}$-substituted 

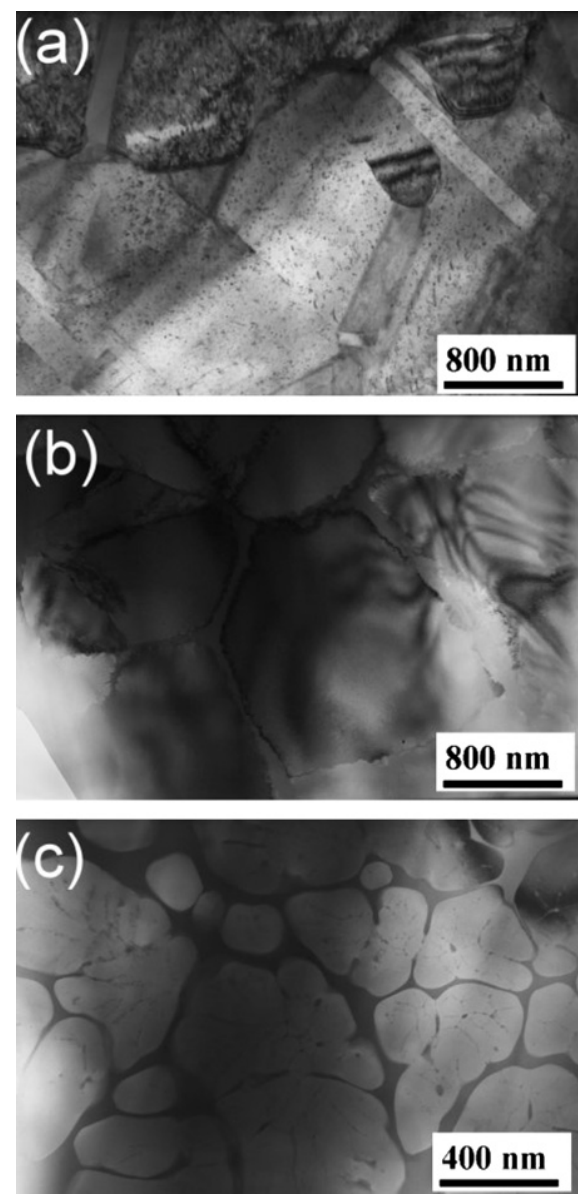

Figure 5. TEM images for directly quenched (a) $\operatorname{Pr}_{9.5} \mathrm{Fe}_{75.5} \mathrm{~B}_{15}$, (b) $\mathrm{Pr}_{9.5} \mathrm{Fe}_{74.5} \mathrm{Nb}_{4} \mathrm{~B}_{12}$ and (c) $\mathrm{Pr}_{9.5} \mathrm{Fe}_{71.5} \mathrm{Nb}_{4} \mathrm{~B}_{15}$ magnets.

magnets, i.e. $\operatorname{Pr}_{9.5} \mathrm{Fe}_{74.5} \mathrm{Nb}_{4} \mathrm{~B}_{12}$ and $\operatorname{Pr}_{9.5} \mathrm{Fe}_{71.5} \mathrm{Nb}_{4} \mathrm{~B}_{15}$. Energy dispersive $\mathrm{X}$-ray analysis (EDX) was used to identify the composition of the grain boundary phase. The EDX result showed that some of the $\mathrm{Nb}$ atoms tended to appear at the grain boundaries. It was presumed that $\mathrm{Nb}$ prefers to react with excess $\mathrm{B}$ to form $\mathrm{Nb}$-boride at the grain boundary, owing to the strong affinity between $\mathrm{Nb}$ and $\mathrm{B}$. On the other hand, the amount of surplus B increased in the boundary with increasing B content, resulting in the formation of larger volume fraction of grain boundary phase in the $\operatorname{Pr}_{9.5} \mathrm{Fe}_{71.5} \mathrm{Nb}_{4} \mathrm{~B}_{15}$ magnet as shown in Figure $5 \mathrm{c}$. The isolation effect of nonmagnetic grain boundary phase on the 2:14:1 phase might play an important role in impeding the domain wall movement and, subsequently, in enhancing the coercivity of the bulk magnets [25]. Based on the above results, the main reasons for the high coercivity achieved for the $\operatorname{Pr}_{9.5} \mathrm{Fe}_{71.5} \mathrm{Nb}_{4} \mathrm{~B}_{15}$ magnets included larger volume fraction of magnetically hard phase (2:14:1), fine grains and the existence of a grain boundary phase that isolated the magnetic grains.

The magnetic properties, phase evolution and microstructure of directly quenched $\operatorname{Pr}_{9.5} \mathrm{Fe}_{90.5-x-y} \mathrm{Nb}_{x} \mathrm{~B}_{y}$ magnets have been examined. The substitution of $\mathrm{Nb}$ for $\mathrm{Fe}$ in bulk $\operatorname{Pr}_{9.5} \mathrm{Fe}_{75.5-x} \mathrm{Nb}_{x} \mathrm{~B}_{15}$ magnetic rods cannot only suppress the formation of an as-yet unidentified phase, resulting in the largest volume fraction of 2:14:1 phase for the compositions studied, but also refine the grain size effectively. Consequently, the magnetic properties of the bulk magnets are improved. The substitution of proper $\mathrm{Nb}$ for $\mathrm{Fe}$ at a high $\mathrm{B}$ concentration, i.e. $y=15$, can greatly modify the phase constitution and refine the grain size from the micrometer scale down to $50-150 \mathrm{~nm}$. Accordingly, the optimal magnetic properties of $J_{\mathrm{r}}=0.57 \mathrm{~T},{ }_{i} H_{\mathrm{c}}=1296 \mathrm{kA} \mathrm{m}^{-1}$ and $(\mathrm{BH})_{\max }=56.8 \mathrm{~kJ} \mathrm{~m}^{-3}$ were achieved for the $\mathrm{Pr}_{9.5^{-}}$ $\mathrm{Fe}_{71.5} \mathrm{Nb}_{4} \mathrm{~B}_{15}$ magnet. The high coercivity arises from the existence of a large volume fraction of the 2:14:1 phase, the fine grain size and the existence of a grain boundary phase that isolates the magnetic grains.

This study was supported by the National Science Council, Taiwan under Grant No. NSC-95-2112-M194-009-MY3.

[1] R. Coehoorn, D.B. DeMooij, C. DeWaard, J. Magn. Magn. Mater. 80 (1989) 101.

[2] A. Manaf, R.A. Buckley, H.A. Davies, M. Leonowicz, J. Magn. Magn. Mater. 101 (1991) 360.

[3] E.F. Kneller, R. Hawig, IEEE Trans. Magn. 27 (1991) 3588.

[4] H. Kanekiyo, M. Uehara, S. Hirosawa, IEEE Trans. Magn. 29 (1993) 2863.

[5] J. Bauer, M. Seeger, A. Zern, H. Kronmüller, J. Appl. Phys. 80 (1996) 1667.

[6] K. Raviprsad, M. Funakoshi, M. Umemoto, J. Appl. Phys. 83 (1998) 921.

[7] W.C. Chang, D.Y. Chiou, S.H. Wu, B.M. Ma, C.O. Bounds, Appl. Phys. Lett. 72 (1998) 121.

[8] M. Yamasaki, M. Hamano, H. Mizuguchi, T. Kobayashi, K. Hono, H. Yamamoto, A. Inoue, Scripta Mater. 44 (2001) 1375.

[9] W. Zhang, A. Inoue, Appl. Phys. Lett. 80 (2002) 1610.

[10] W. Zhang, A. Inoue, J. Appl. Phys. 91 (2002) 8834.

[11] P. Pawlik, H.A. Davies, Scripta Mater. 49 (2003) 755.

[12] M. Marinescu, P.C. Pawlik, H.A. Davies, H. Chiriac, J. Optoelectron. Adv. Mater. 6 (2004) 603.

[13] M. Marinescu, H. Chiriac, M. Grigoras, J. Magn. Magn. Mater. 290 (2005) 1267.

[14] J. Zhang, K.Y. Kim, Y.P. Feng, Y. Li, Scripta Mater. 56 (2007) 943.

[15] H.W. Chang, C.H. Chiu, W.C. Chang, Appl. Phys. Lett. 82 (2003) 4513.

[16] C.H. Chiu, H.W. Chang, W.C. Chang, J. Magn. Magn. Mater. 282 (2004) 186.

[17] C.H. Chiu, H.W. Chang, C.W. Chang, W.C. Chang, IEEE Trans. Magn. 41 (2005) 3769.

[18] H.W. Chang, C.H. Chiu, W.C. Chang, IEEE Trans. Magn. 40 (2004) 2871.

[19] H.W. Chang, C.H. Chiu, C.W. Chang, C.H. Chen, W.C. Chang, Y.D. Yao, A.C. Sun, J. Alloys Compd. 407 (2006) 53.

[20] H.W. Chang, C.H. Chiu, C.W. Chang, W.C. Chang, A.C. Sun, Y.D. Yao, Scripta Mater. 55 (2006) 529.

[21] C.H. Chiu, H.W. Chang, C.W. Chang, W.C. Chang, Scripta Mater. 56 (2007) 429.

[22] I. Betancourt, H.A. Davies, Appl. Phys. Lett. 87 (2005) 162516.

[23] I. Betancourt, H.A. Davies, Physica B 384 (2006) 286.

[24] Y. Long, W. Zhang, X. Wang, A. Inoue, J. Appl. Phys. 91 (2002) 5227.

[25] E. Girt, K.M. Krishnan, G. Thomas, Z. Altounian, Appl. Phys. Lett. 76 (2000) 1746. 